\title{
A New Adaptive Control Scheme for Induction Heating System
}

\author{
Laboratoire de Génie Electrique et Energies Renouvelables, \\ Université Hassiba Benbouali, \\ Hay Salem, route nationale $\mathrm{N}^{\circ} 19,02000$ Chlef, Algérie \\ halimi1976@yahoo.fr
}

M'Hamed HELAIMI*, Djilali BENYOUCEF, Rachid TALEB, Bachir BELMADANI

\begin{abstract}
This paper proposes the design of a new adaptive power control scheme for full bridge series-parallel resonant inverter with AVC control strategy. This scheme is used to control the heating process by adjusting the output power of the inverter irrespective of load and line variations. Two independent control loops are used in this technique: power control loop and frequency control loop (PLL). In the first, an adaptive PID controller with parallel structure is used to force the output power to track the desired trajectory. The adaptive PI controller of the PLL varies the DC input of the VCO in order to generate the required output frequency to maintain ZVS operating during the heating process. The desired performances of the closed loop control are given by two independent reference models. The design of the adaptive mechanism is based on MIT rule and the small signal model of the inverter around the operating point. Compared with other works, the adaptive mechanism redesigns the parameter gains of the PID and the PI controllers in order to avoid the disturbance. Simulation results confirm the effectiveness of the proposed system.
\end{abstract}

Keywords: H Bridge Resonant Inverter, Induction Heating, PLL, PI, PID, MIT rule, Design, Simulation.

\section{Introduction}

Induction heating is a very complex process that involves multi-physics couplings such as electromagnetic, thermal and mechanical. Its application permits to heat a ferromagnetic work piece with better heat distribution, more accuracy and low power consumption [1]-[2].

Recently, a full bridge series-parallel resonant inverter with AVC control strategies is the most widely used topology due to its high reliability. This structure can deliver three level output voltage from DC input voltage [3]-[8].

Induction heating systems are known as complex non linear multivariable problems in which a time-varying structure and parameters variation during the heating phase entail an additional difficulty for modeling and control purposes [9]. Generally, Extending Describing Function methods are used to establish a small signal model of the overall system from any desired input to any desired output [9]-[13].

In control practice, the closed control diagram of induction heating system consists of two control loops: power control loop and frequency control loop (PLL) [9]-[11]. A PID controller with parallel structure is the most popular algorithm used in power control loop [14]-[15]. The conventional PLL with a phase comparator, a low pass filter and linear voltage controlled oscillator (VCO) is the most used [16]. Performance of these control loops with constant gain of PID and PLL diminishes under disturbance and load variations. This problem can be solved by using adaptive control techniques.

Compared with other papers [17]-[20], the basic idea of this work is to propose a new power control scheme based on two adaptive control loops. In the frequency control loop, an adaptive PI controller is introduced between the phase detector and the VCO. This controller is used to adjust the DC input voltage of the VCO for tracking the resonant frequency of the system in order to maintain the ZVS operation during the heating process. In the power control loop, an adaptive PID controller with a parallel structure is used to adjust the shifted angle of the switches to control the output power of the inverter. The required performances of two control loops are expressed by two reference models. An adaptive mechanism based on MRAC and MIT rule [21]-[28] is used to redesigns the gains parameters of PI and PID controllers in accordance to the change in the induction heating system and the rectifier.

This paper is organized as follows: the resonant inverter configuration and the complete closed loop diagram of the proposed control are given in Section 2 and 3, respectively. A Generalized small signal model of the overall system is developed in Section 4. The adaptive power control scheme controller design is introduced in Section 5. Some simulation results are given in Section 6. Finally, Section 7 concludes this paper. 


\section{LLC Resonant Inverter}

This Section describes the simplified topology of the proposed H-bridge inverter with LLC resonant tank. This configuration includes a DC power supply $V_{i}$ and four MOSFET switches $\mathrm{T}_{1} \sim \mathrm{T}_{4}$ with external freewheeling diodes $\mathrm{D}_{1} \sim \mathrm{D}_{4}$. The oscillating circuit given in Figure 1 [3] is composed of a series inductor $L_{s}$ with a parallel resonant capacitor $C$. The induction heating load (copper coil and workpiece) can be modeled by means of a series combination of its equivalent resistance $R$ and equivalent inductance $L$ transferred to the primary side of the matching transformer [9], [30].

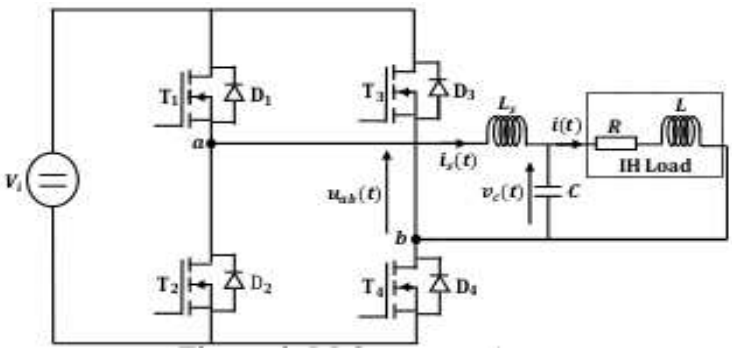

Figure 1. LLC resonant inverter

The converter is operated at frequency above the natural one for the LLC load given by [3]:

$\omega_{0}=\sqrt{\frac{L+L_{s}}{L . C \cdot L_{s}}}$

According to the switch on-off conditions [4] the typical waveform of the applied voltage $u_{a b}(t)$ is given in Figure 2:

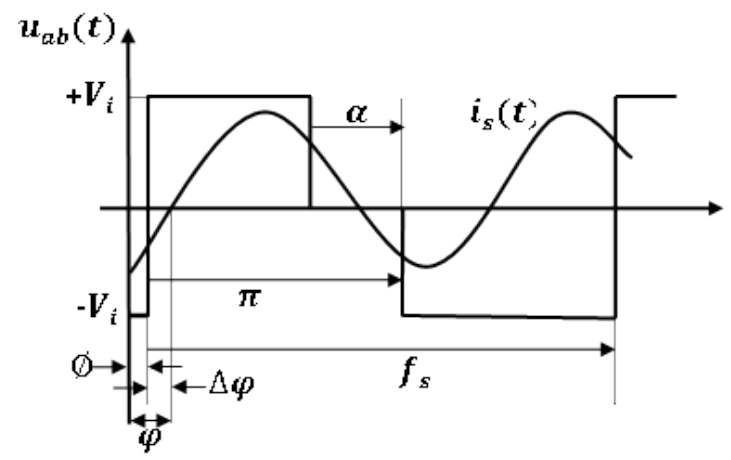

Figure 2. Typical waveforms of the applied voltage

The condition for ZVS operation in all devices of the full-bridge series-parallel resonant inverter is [4]:

$$
\Delta \varphi=\varphi-\varnothing>0
$$

When the temperature of the workpiece increases during the heating phase, the natural frequency of the system varies. The PLL circuit tracks the natural frequency of the load to maintain the ZVS operation. The controller adjusts the shifted angle $\alpha$ to reduce the output power [3]-[4].

To control the heating process of the workpiece from $30^{\circ} \mathrm{C}$ to $625^{\circ} \mathrm{C}$, the switching frequency, $f_{s}$, and the angle, $\alpha$, must be varied between $[108.7 \mathrm{kHz}, 110 \mathrm{kHz}]$ and $\left[36^{\circ}, 144^{\circ}\right]$, respectively [3].

Figure 3 shows the measured output power $P$ as function of the shifted angle $\alpha$ :

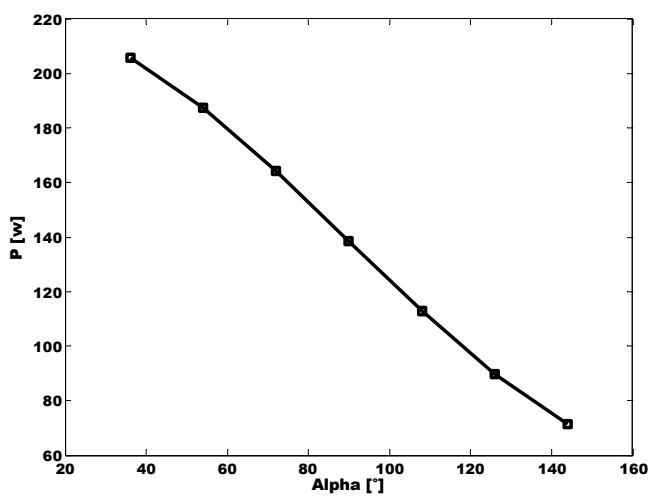

Figure 3. Measured output power versus $\alpha$

When the shifted angle is increased from $36^{\circ}$ to $144^{\circ}$, the measured output power decrease from $205.8 w$ to $71.26 w$. This means that $\alpha$ can be varied to adjust the output power of the $\mathrm{H}$-bridge resonant inverter.

Figure 4 depicts the measured total harmonic distortion THD of the applied voltage $u_{a b}(t)$ and the input current $i_{s}(t)$ as a function of the shifted angle $\alpha$ :

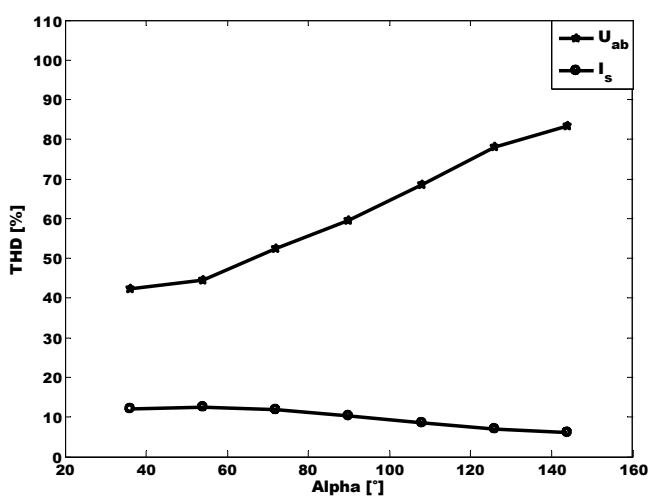

Figure 4. Measured THD versus $\alpha$

When the shifted angle is increased from $36^{\circ}$ to $144^{\circ}$, the measured THD of $u_{a b}(t)$ increases from 42.23 to 83.42 and the measured THD of $i_{s}(t)$ decreases from 12.05 to 6 . 
Notice that the THD of the current waveform is significantly reduced compared to that of the applied voltage. This harmonic content has been filtered by the load inductance.

\section{Proposed Adaptive Control}

The basic scheme of the proposed adaptive closed loop control is given in figure 5. The scheme can be divided into two loops: power control loop and frequency control loop. In the first loop, the PID controller is used to adjust the duty cycle $D$ of the switch $\mathrm{T}_{4}$ in order to maintain constant the output power even if the parameters are varied. The PLL imposes the desired frequency $\omega_{s}$ to maintain $\Delta \varphi>0$.

A desired performance that the overall system is required to track during the heating process is expressed in terms of two references model $G_{M R 1}(s)$ and $G_{M R 2}(s)$ excited by a reference command input $P_{r}$ and $\Delta \varphi_{r}$, respectively. The choice of $G_{M R 1}(s)$ and $G_{M R 1}(s)$ reflect the performance specifications in the control tasks, such as rise time, overshoot and settling time.

The adaptive mechanism based on MIT rules receives the following signals $\varepsilon_{p}, \varepsilon_{\varphi}, \Delta \varphi$, $P, e_{p}$ and $e_{\varphi}$ from the system to adjusts the controller parameters of PI and PID structures on the basic of the tracking errors $e_{p}$ and $e_{\varphi}$, which are the difference between unknown plants output and reference models output. The main objective of this control is to synthesize an adaptive mechanism which will guarantee the stability of the system and minimize the tracking error irrespective of load and line variations.

\section{Dynamic Model of the System}

Recently, many published researches have been focused on modelling and control of resonant inverter topologies used in induction heating system [13]. The most used technique based on the first harmonic approximation of the state variables is called EDF method [11]. This approach is used to develop a linear model of the overall system valid around the operating point. In this section, we present briefly the EDF method used to establish a linear mathematical model of the H-bridge LLC resonant inverter with AVC control strategy. First, we give the differential nonlinear equations that describe the circuit given in Figure 1:

$$
\left\{\begin{array}{l}
\dot{i}_{s}(t)=\frac{-1}{L_{s} \cdot C} \cdot i_{s}(t)+\frac{1}{L_{s} \cdot C} \cdot i(t)-\frac{1}{L_{s}} \cdot \dot{u}_{a b}(t) \\
\dot{i}(t)=\frac{1}{L \cdot C} \cdot i_{s}(t)-\frac{1}{L \cdot C} \cdot i(t)-\frac{R}{L} \cdot \dot{i}(t) \\
\dot{v}_{c}(t)=\frac{1}{C} \cdot i_{s}(t)-\frac{1}{C} \cdot i(t)
\end{array}\right.
$$

The state vector is chosen as:

$$
x(t)=\left[i_{s}(t) v_{c}(t) i(t)\right]^{t}
$$

The input variable $u(t)$ and the output variable $y(t)$ are given as:

$$
\begin{aligned}
& u(t)=u_{a b}(t) \\
& y(t)=\frac{1}{2} \cdot R \cdot i^{2}(t)(6)
\end{aligned}
$$

The nonlinear model of (3) is used by decomposing the state variables vector into $d$ and $q$ waveforms:

$$
\left\{\begin{array}{c}
\left\langle i_{s}\right\rangle_{1}=i_{s d}+j \cdot i_{s q} \\
\left\langle v_{c}\right\rangle_{1}=v_{c d}+j \cdot v_{c q} \\
\langle i\rangle_{1}=i_{d}+j \cdot i_{q}
\end{array}\right.
$$

The first harmonic of the applied voltage $u_{a b}(t)$ is calculated as:

$$
\left\langle u_{a b}\right\rangle_{1}=\frac{V_{i}}{\pi} \cdot[\sin (\pi-\alpha)]+j \frac{V_{i}}{\pi} \cdot[3-\cos (\pi-\alpha)]
$$

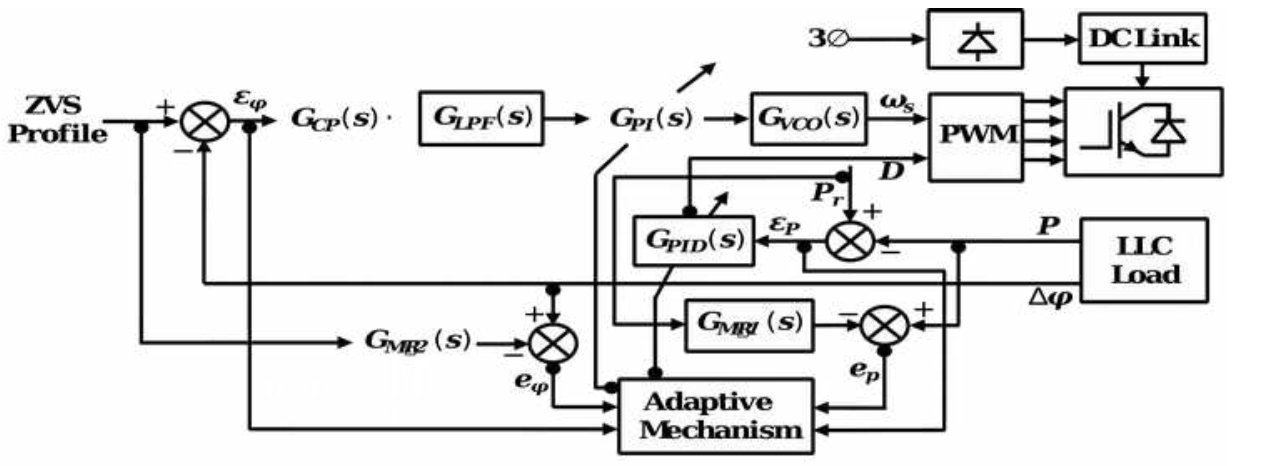

Figure 5. Proposed adaptive power control scheme 
The first harmonic approximation of $i_{s}(t)$, $v_{c}(t)$ and $i(t)$ are acceptable when $Q \gg 1$ and $\omega_{s} \approx \omega_{0}$.

The large signal model of the system is developed by replacing (7)-(8) into (3) and using harmonic balance procedure to decompose (3) into six equations [10]-[11]. Introducing perturbation in state variables:

$$
\left\{\begin{array}{c}
i_{s d}(t)=I_{s d 0}+\tilde{i}_{s d}(t) \\
i_{s q}(t)=I_{s q 0}+\tilde{i}_{s q}(t) \\
v_{c d}(t)=V_{c d 0}+\tilde{v}_{c d}(t) \\
v_{c q}(t)=V_{c q 0}+\tilde{v}_{c q}(t) \\
i_{d}(t)=I_{d 0}+\tilde{i}_{d}(t) \\
i_{q}(t)=I_{q 0}+\tilde{i}_{q}(t)
\end{array}\right.
$$

where:

$$
\mid \begin{aligned}
& \tilde{i}_{s d}(t) \ll I_{s d 0} \\
& \tilde{i}_{s q}(t) \ll I_{s q 0} \\
& \tilde{v}_{c d}(t) \ll V_{c d 0} \\
& \tilde{v}_{c q}(t) \ll V_{c q 0} \\
& \tilde{i}_{d}(t) \ll I_{d 0} \\
& \tilde{i}_{q}(t) \ll I_{q 0}
\end{aligned}
$$

Notice that the input variables $\alpha$ and $\omega_{s}$ are implicitly included in the output voltage $u_{a b}(t)$. Introducing perturbation in input variables:

$$
\left\{\begin{array}{c}
\alpha(t)=\alpha_{0}+\widetilde{\alpha}(t) \\
\omega_{s}(t)=\omega_{s 0}+\widetilde{\omega}_{s}(t)
\end{array}\right.
$$

where:

$$
\left\{\begin{array}{c}
\tilde{\alpha}(t) \ll \alpha_{0} \\
\widetilde{\omega}_{s}(t) \ll \omega_{s 0}
\end{array}\right.
$$

By using the Taylor series, the state space small signal model of the system is derived by perturbation and linearization of large signal model around the operating point $\left(\alpha_{0}, \omega_{s 0}\right.$, $\left.V_{i 0}, I_{s d 0}, I_{s q 0}, V_{c d 0}, V_{c q 0}, I_{d 0}, I_{q 0}\right)$ :

$$
\left\{\begin{array}{c}
\dot{\tilde{x}}(t)=A_{s} \cdot \tilde{x}(t)+B_{s} \cdot \tilde{u}(t) \\
\tilde{y}(t)=C_{s} \cdot \tilde{x}(t)
\end{array}\right.
$$

where:

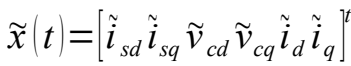

$$
\begin{aligned}
& \tilde{u}(t)=\left[\begin{array}{ll}
\widetilde{\alpha} & \widetilde{\omega}_{s}
\end{array}\right]^{t} \\
& \tilde{y}(t)=\widetilde{P}(t)
\end{aligned}
$$

$$
\begin{aligned}
& A_{s}=\left|\begin{array}{cccccc}
0 & -\omega_{s 0} & \frac{-1}{L_{s}} & 0 & 0 & 0 \\
\omega_{s 0} & 0 & 0 & \frac{-1}{L_{s}} & 0 & 0 \\
\frac{1}{C} & 0 & 0 & -\omega_{s 0} & \frac{-1}{C} & 0 \\
0 & \frac{1}{C} & \omega_{s 0} & 0 & 0 & \frac{-1}{C}
\end{array}\right| \\
& \begin{array}{llllll}
0 & 0 & \frac{1}{L} & 0 & \frac{-R}{L} & -\omega_{s 0}
\end{array} \\
& \begin{array}{llllll}
0 & 0 & 0 & \frac{1}{L} & \omega_{s 0} & \frac{-R}{L}
\end{array} \\
& B_{s}=\left|\begin{array}{cc}
\frac{-V_{i 0}}{\pi \cdot L_{s}} \cdot \cos \left(\pi-\alpha_{e}\right) & -X_{1 q 0} \\
\frac{-V_{i 0}}{\pi \cdot L_{s}} \cdot \sin \left(\pi-\alpha_{e}\right) & X_{1 d 0} \\
0 & X_{2 q 0} \\
0 & X_{2 d 0} \\
0 & -X_{3 q 0} \\
0 & X_{3 d 0}
\end{array}\right| \\
& C_{s}=\left[\begin{array}{llllll}
0 & 0 & 0 & 0 & R \cdot I_{d 0} & R . I_{q 0}
\end{array}\right]
\end{aligned}
$$

The following small signal transfer function of the output power variation due to the shifted angle change is obtained:

$$
G_{\alpha}(s)=\frac{\widetilde{P}_{1}(s)}{\widetilde{\alpha}(s)}=C_{s} \cdot\left(s . I-A_{s}\right)^{-1} \cdot B_{\alpha}
$$

The small signal transfer function from the input frequency to the output power is derived as follow:

$$
G_{\omega}(s)=\frac{\widetilde{P}_{1}(s)}{\widetilde{\omega}_{s}(s)}=C_{s} \cdot\left(s \cdot I-A_{s}\right)^{-1} \cdot B_{\omega}
$$

To verify the above analysis and calculation of $G_{\alpha}(s)$ and $G_{\omega}(s)$, a numerical simulation is used to compare the predicted magnitude $\left|G_{\alpha}(s)\right|$ and $\left|G_{\omega}(s)\right|$ with the measured ones. The obtained results are given in Figures 6 and 7.

From the simulation results, the agreement is quite good. It is confirmed that the obtained small signal model transfer functions represents rather accurately the real system around the operating point. This is justified by the capability of the EDF technique to derive linear accuracy state space models of the nonlinear system from any desired input to any desired output. The resulting linear model is used for synthesis of the adaptive control law. 


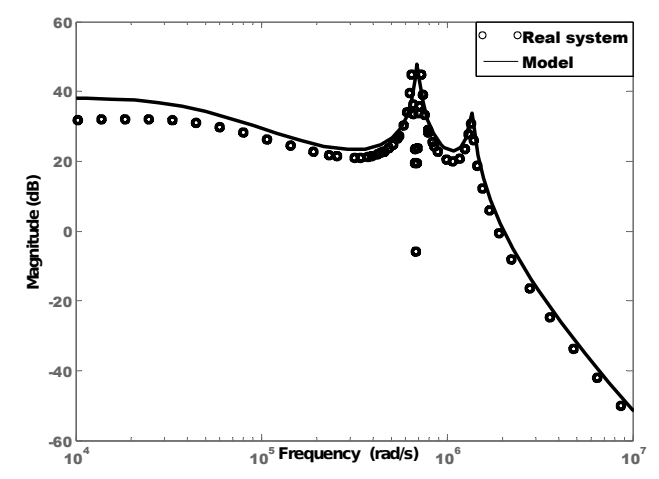

Figure 6. Bode plot of $G_{\alpha}(s)$

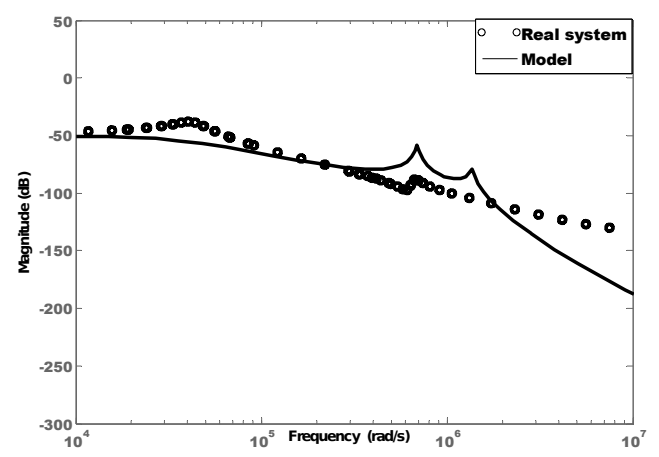

Figure 7. Bode plot of $G_{\omega}(s)$

\section{Design of PI and PID Controllers}

In this Section, a design of adaptive power control scheme using MRAC and MIT rule for $\mathrm{H}$ bridge series-parallel resonant inverter for induction application is proposed. This scheme is composed of two control loops: frequency control loop and power control loop. The adaptive mechanism adjusts the parameters of both controllers (PI and PID) in order to reach a desired level of performances given by a two proposed reference models. The design of the two control loops are given separately:

\subsection{Frequency control loop}

Phase-locked loops are widely used in induction heating system to track the natural frequency of the system to maintain ZVS operation during the heating phase. It's based on the phase difference between the input signal $\Delta \widetilde{\varphi}_{r}$ and the measured one $\Delta \widetilde{\varphi}$. Figure 8 shows a block diagram of the PLL integrated with the $\mathrm{H}$ bridge resonant inverter.

The phase detector compares $\Delta \widetilde{\varphi}_{r}$ and $\Delta \widetilde{\varphi}$ and generates an error signal $\Delta \widetilde{\varphi}_{e}$ proportional to the phase difference between the two inputs:

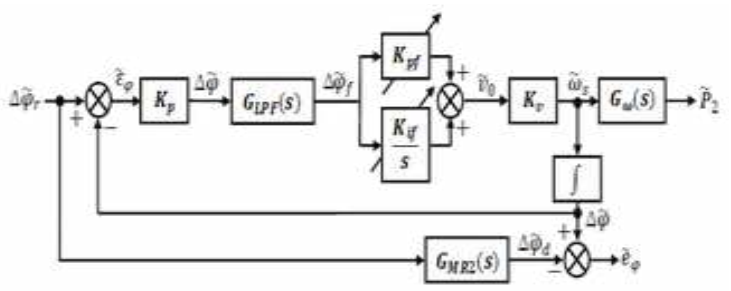

Figure 8. Bloc diagram of the proposed PLL

$$
\Delta \tilde{\varphi}_{e}=K_{p} \cdot\left(\Delta \tilde{\varphi}_{r}-\Delta \tilde{\varphi}\right)
$$

A low pass filter $G_{L P F}(s)$ is used to eliminate high frequency component of the resulting signal and produces a low frequency error signal $\Delta \tilde{\varphi}_{f}$.

$$
G_{L P F}(s)=\frac{\tau_{1} \cdot s+1}{\tau_{2} \cdot s}
$$

The filter parameters $\tau_{1}$ and $\tau_{2}$ are calculated based on the operating frequency of the system.

The adaptive PI controller adjusts the DC input voltage $v_{0}$ of the $\mathrm{VCO}$ in order to generate the desired switching frequency to the inverter minimizing the phase error between $\Delta \widetilde{\varphi}_{r}$ and $\Delta \widetilde{\varphi}$. The input signal $\widetilde{v}_{0}$ is expressed as:

$\tilde{v}_{0}(s)=\left(K_{p f}+\frac{K_{i f}}{s}\right) \cdot \Delta \tilde{\varphi}_{f}$

where, $K_{p f}$ and $K_{i f}$ are the adjustable parameters of the PI controller.

The VCO characteristic is a linear with slope $K_{v}$ so that any change in $\tilde{v}_{0}$ will produce VCO output frequency change $\Delta \widetilde{\omega}_{s}$.

To improve the performances of the closed loop system, the PI controller is designed by using MIT rule. This technique requires the appropriate choice of the reference model $G_{M R 2}(s)$. The adjustment mechanism adjusts the parameters of the PI controller minimizing the tracking error $\tilde{e}_{\varphi}$ between the system output and the reference model with minimum time as possible to maintain ZVS operation. The cost function for adaptation is given by:

$J\left(\theta_{1}\right)=\frac{1}{2} \cdot \tilde{e}_{\varphi}^{2}\left(\theta_{1}\right)$

where:

$$
\begin{aligned}
& \theta_{1}=\left\{K_{p f}, K_{i f}\right\} \\
& \tilde{e}_{\varphi}=\Delta \widetilde{\varphi}_{r}-\Delta \widetilde{\varphi}_{d}
\end{aligned}
$$

According to the MIT rule, the change in the parameter $\theta_{1}$ is kept in the direction of the negative gradient of $j\left(\theta_{1}\right)$ : 
$\frac{d \theta_{1}}{d t}=-\gamma \cdot \frac{\partial J\left(\theta_{1}\right)}{\partial \theta_{1}}=-\gamma \cdot \tilde{e}_{\varphi} \cdot \frac{\partial \tilde{e}_{\varphi}\left(\theta_{1}\right)}{\partial \theta_{1}}$

where $\frac{\partial \tilde{e}_{\varphi}\left(\theta_{1}\right)}{\partial \theta_{1}}$ is the sensitivity derivative of error with respect to $\theta_{1}$ and $\gamma$ is known as the adaptation gain.

To achieve a short transient time with little overshoot, the reference model is chosen to satisfy the following conditions:

- The overshoot is less the 20

- The rise time $t_{r}$ is less then $140 \mu \mathrm{s}$

- $\quad$ The settling time $t_{s}$ is less then $910 \mu \mathrm{s}$

The open loop transfer function of the PLL is expressed as:

$$
H(s)=\frac{N_{f}(s)}{\tau_{2} \cdot s^{3}}
$$

where:

$$
\begin{aligned}
N_{f}(s) & =K_{p} \cdot K_{v} \cdot \tau_{1} \cdot K_{p f} \cdot s^{2} \\
& +K_{p} \cdot K_{v} \cdot\left(\tau_{1} \cdot K_{i f}+K_{p f}\right) \cdot s \\
& +K_{p} \cdot K_{v} \cdot K_{p f}
\end{aligned}
$$

Using (18) and the closed loop transfer function of the PLL the adjustment of the controller parameters can be obtained as:

$$
\begin{aligned}
\frac{d K_{p f}}{d t} & =\frac{-\gamma_{p f} \cdot \tilde{e}_{\varphi} \cdot N_{1 f}(s) \cdot\left[\Delta \tilde{\varphi}_{r}-\Delta \widetilde{\varphi}\right]}{D_{f}(s)} \\
\frac{d K_{i f}}{d t} & =\frac{-\gamma_{p f} \cdot \tilde{e}_{\varphi} \cdot N_{2 f}(s) \cdot\left[\Delta \widetilde{\varphi}_{r}-\Delta \widetilde{\varphi}\right]}{D_{f}(s)}
\end{aligned}
$$

where:

$$
\begin{aligned}
& N_{1 f}(s)=\left(K_{p} \cdot K_{v} \cdot \tau_{1} \cdot s^{2}+K_{p} \cdot K_{v} \cdot s\right) \\
& \begin{aligned}
N_{2 f}(s) & =\left(K_{p} \cdot K_{v} \cdot \tau_{1} \cdot s+K_{p} \cdot K_{v}\right) \\
D_{f}(s) & =\tau_{2} \cdot s^{3}+K_{p} \cdot K_{v} \cdot \tau_{1} \cdot K_{p f} \cdot s^{2} \\
& +K_{p} \cdot K_{v} \cdot\left(\tau_{1} \cdot K_{i f}+K_{p f}\right) \cdot s \\
& +K_{p} \cdot K_{v} \cdot K_{p f}
\end{aligned}
\end{aligned}
$$

\subsection{Power control loop}

Figure 9 shows the small signal model of the proposed power loop system for $\mathrm{H}$ bridge LLC inverter.

The adaptive PID controller is used to improve the performance of the closed loop system under disturbances. Based on the error signal, the proposed controller adjusts the shifted angle $\tilde{\alpha}$ to make the output power follow the

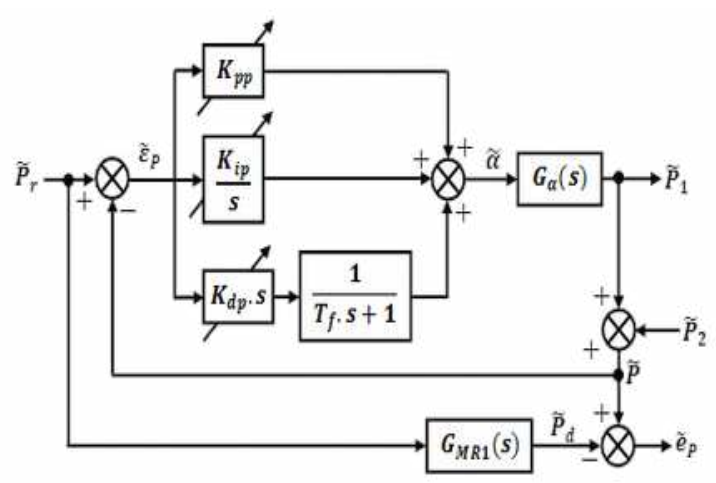

Figure 9. Small signal model of the power control loop

reference value irrespective of load variations. The controlled shifted angle is given by:

$$
\tilde{\alpha}(s)=\left(K_{p p}+\frac{K_{i p}}{s}+K_{d p} \cdot s \cdot \frac{1}{T_{f} \cdot s+1}\right) \cdot \tilde{\varepsilon}_{p}(s)
$$

where, $K_{p p}, K_{i p}$ and $K_{d p}$ are the adjustable parameters of the PID controller. $T_{f}$ is the filter time constant.

The design of the PID controller is based on the small signal model of the proposed resonant inverter about the nominal operating point.

The closed loop transfer function of the system shown in Figure 9 is:

$$
\frac{\widetilde{P}(s)}{\widetilde{P}_{r}(s)}=\frac{N_{p}(s) \cdot G_{\alpha}(s)}{D_{p}(s)}
$$

where:

$$
\begin{aligned}
N_{p}(s) & =K_{d p} \cdot s^{2}+K_{p p} \cdot s \cdot\left(T_{f} \cdot s+1\right) \\
& +K_{i p} \cdot\left(T_{f} \cdot s+1\right) \\
D_{p}(s) & =s \cdot\left(T_{f} \cdot s+1\right)+\left[K_{d p} \cdot s^{2}\right. \\
& +K_{p p} \cdot s \cdot\left(T_{f} \cdot s+1\right) \\
& \left.+K_{i p} \cdot\left(T_{f} \cdot s+1\right)\right] \cdot G_{\alpha}(s)
\end{aligned}
$$

The adaptive mechanism adjusts the controller parameters $K_{p p}, \quad K_{i p}$ and $K_{d p}$ to achieve a desired closed-loop performance given by the reference model $G_{M R 1}(s)$.

The mathematic procedure to design the PID controller is based on the minimization of the cost function given by the following expression:

$$
J\left(\theta_{2}\right)=\frac{1}{2} \cdot \tilde{e}_{P}^{2}\left(\theta_{2}\right)
$$

where:

$$
\theta_{2}=\left\{K_{p p}, K_{i p}, K_{d p}\right\}
$$$$
\tilde{e}_{P}=\widetilde{P}_{r}-\widetilde{P}_{d}
$$ 
It is reasonable to change $\theta_{2}$ in the direction of the negative gradient of $J\left(\theta_{2}\right)$ that is:

$\frac{d \theta_{2}}{d t}=-\gamma \cdot \frac{\partial J\left(\theta_{2}\right)}{\partial \theta_{2}}=-\gamma \cdot \tilde{e}_{P} \cdot \frac{\partial \tilde{e}_{P}\left(\theta_{2}\right)}{\partial \theta_{2}}$

$\frac{\partial \tilde{e}_{P}\left(\theta_{2}\right)}{\partial \theta_{2}}$ is called the sensitivity derivative of error $\tilde{e}_{P}\left(\theta_{2}\right)$.

The resulting adaptive law is given by:

$$
\begin{aligned}
& \frac{d K_{p p}}{d t}=\frac{-\gamma_{p p} \cdot \tilde{e}_{P} \cdot N_{1 p}(s) \cdot\left[\widetilde{P}_{r}-\widetilde{P}\right]}{D_{1 p}(s)} \\
& \frac{d K_{i p}}{d t}=\frac{-\gamma_{i p} \cdot \tilde{e}_{P} \cdot N_{2 p}(s) \cdot\left[\widetilde{P}_{r}-\widetilde{P}\right]}{D_{1 p}(s)} \\
& \frac{d K_{d p}}{d t}=\frac{-\gamma_{d p} \cdot \tilde{e}_{P} \cdot N_{3 p}(s) \cdot\left[\widetilde{P}_{r}-\widetilde{P}\right]}{D_{1 p}(s)}
\end{aligned}
$$

where:

$$
\begin{aligned}
N_{1 p}(s) & =s \cdot\left(T_{f} \cdot s+1\right) \cdot G_{\alpha}(s) \\
N_{2 p}(s) & =\left(T_{f} \cdot s+1\right) \cdot G_{\alpha}(s) \\
N_{3 p}(s) & =s^{2} \cdot G_{\alpha}(s) \\
D_{1 p}(s) & =s \cdot\left(T_{f} \cdot s+1\right) \\
& +\left[K_{d p} \cdot s^{2}+K_{p p} \cdot s \cdot\left(T_{f} \cdot s+1\right)\right. \\
& \left.+K_{i p} \cdot\left(T_{f} \cdot s+1\right)\right] \cdot G_{\alpha}(s)
\end{aligned}
$$

The reference model $G_{M R 1}(s)$ is selected in such a way to get the closed loop response with rise time $<60 \mu \mathrm{s}$, overshoot $<10$ and settling time $<180 \mu \mathrm{s}$.

\section{Simulation Results}

The $\mathrm{H}$ bridge resonant inverter in Figure 1 and its power control scheme in Figure 4 are implemented numerically using MATLAB/SIMULINK where the numerical values of the system parameters are given in Appendix. The aim of these simulations is to verify the performance of the proposed control scheme designed in Section 5.

The main objectives of this control are:

- To maintain constant the output power of the inverter irrespective of load and line variations.

- Maintain $\Delta \varphi>0$ to ensure soft-switching during the heating cycle.

- Ensure controlled heating process by introducing PI and PID controllers.
- Maintain stability and precision of the closed loop system.

In this paper, a PLL is used to control the phase difference $\Delta \varphi$ between the applied voltage and the output current to maintain ZVS operation. The parameters of this system are designed according to the resonant frequency of the system. The transient time and the frequency responses of the closed loop system are checked to verify the performance specifications after the control design of the PLL. The obtained simulation results are given by the following Figures (10 and 11).

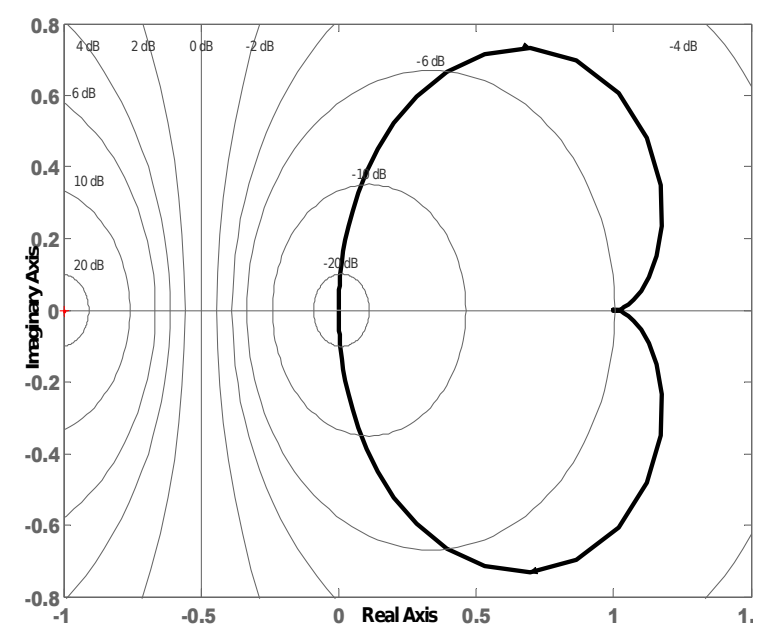

Figure 10. Nyquist plot of the PLL

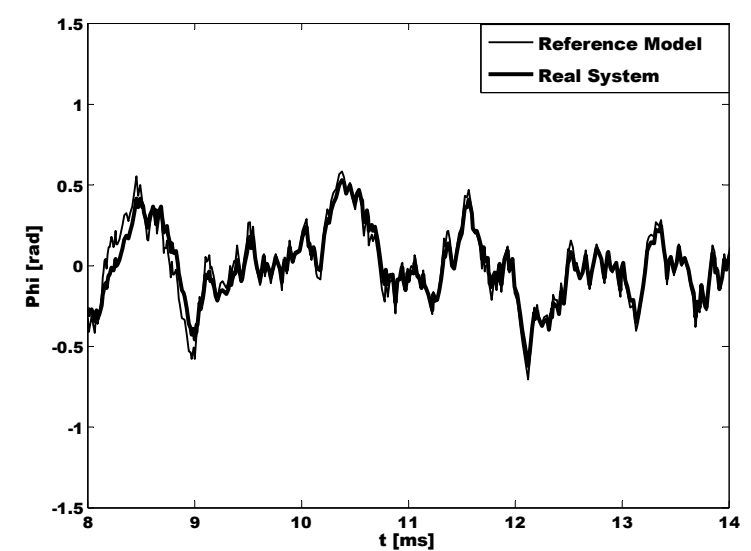

Figure 11. Closed loop response of the PLL

From these figures, the phase margin is $133^{\circ}$ which indicates that the system is stable. It can be observed that the proposed PLL has achieved a good tracking of reference model trajectories and maintained $\Delta \varphi$ constant between the two signals.

To evaluate the performances of the proposed adaptive PID controller, we compare firstly the response results of the real system and the reference model for a sinus reference variation. 
Figures 12 and 13 show the comparison results and the corresponding tracking error $e_{P}(t)$ :

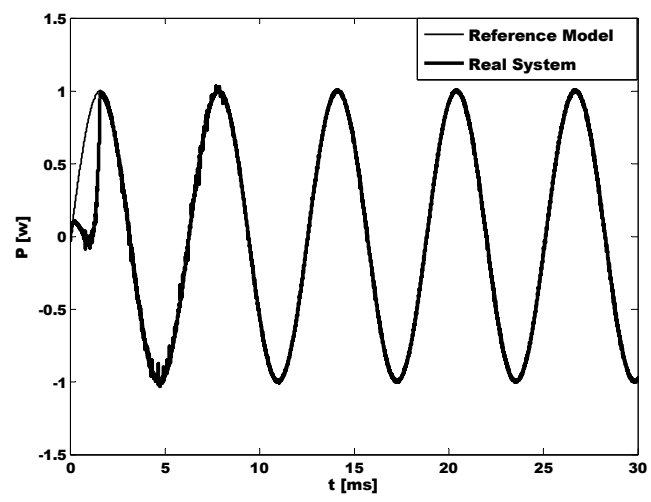

Figure 12. Closed loop response of proposed power control scheme

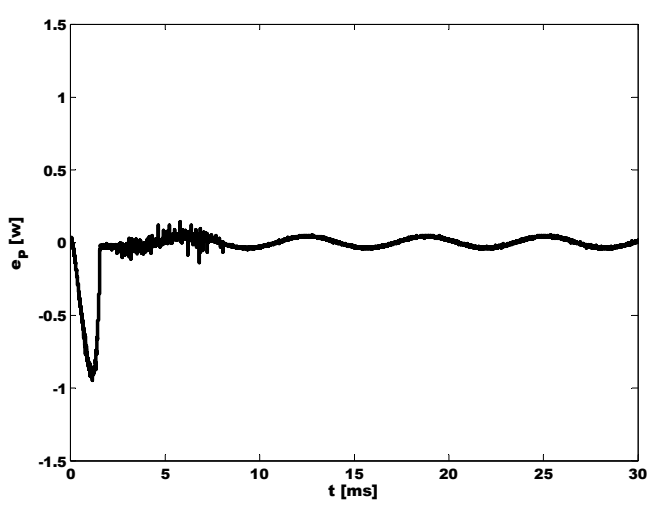

Figure 13. Tracking error variation $e_{P}$

These figures show the ability of the proposed control technique to force the system output power to track the reference model. This is justified by: the appropriate choice of the adaptation gains $\gamma_{p p}, \quad \gamma_{i p}$ and $\gamma_{d p}$ are responsible to improve the transient performance of the output power in terms of rise time, overshoot and settling time.

In order to test the robustness of the proposed control power scheme to load and line variations, the load resistance $R$ and the input voltage $V_{i}$ have been stepped in large range during the simulation. These variations affect the system at time, $t=14 \mathrm{~ms}$ while the system was already stabilized to the desired output power. The changes in load resistance $R$ and input voltage $V_{i}$ were set to 30 and 20 of its nominal values, respectively. The resulting tracking errors $e_{P}$ in both cases are given in Figure 14 and 15, respectively.

The disturbance rejection is achieved by forcing the system to follow the output of the reference model by modifying the input. In this case, the control parameters converge to a constant value and the tracking error $e(t)$ is tends to zero.

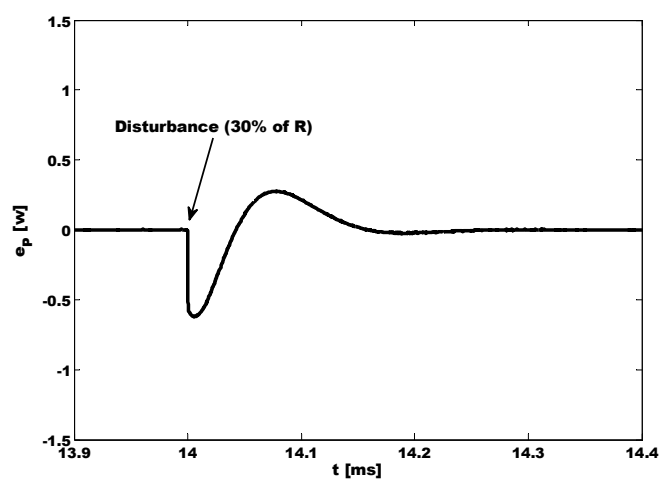

Figure 14. Tracking error variation $e_{P}$ under load variation

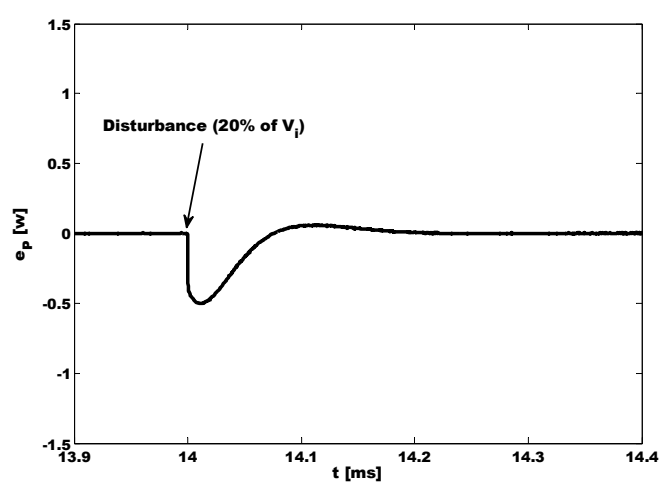

Figure 15. Tracking error variation $e_{P}$ under line variation

\section{Conclusion}

In this paper, a design of adaptive power control scheme using MRAC and MIT rule for a full bridge series-parallel resonant inverter for induction heating application has been proposed. The linear mathematical model of the system is derived using Extended Describing Function method. Numerical simulation confirms the accuracy of the resulting model. In control based approach, the proposed adaptive mechanism can adjust the controller parameters in order to force the output power of the plant to follow the desired performance given by the specified reference models corresponding to changes of plant and line disturbance. The main advantage of this approach is that the exact shape of the disturbance function does not need to be known in advance. From the simulation results, it is shown that the adaptive mechanism needs the 
appropriate choice of the adaptation gain to ensure better performance.

\section{Appendix A.}

The operating point used in this study is given in the Table 1[3]:

Table1. Operating point

\begin{tabular}{|c|c|}
\hline$R$ & $2.5 \Omega$ \\
\hline$L$ & $27.7 \mu \mathrm{H}$ \\
\hline$C$ & $94 \mathrm{n} . \mathrm{F}$ \\
\hline$L_{s}$ & $144 \mu \mathrm{H}$ \\
\hline$V_{i}$ & $150 \mathrm{v}$ \\
\hline$\alpha_{e}$ & $90^{\circ}$ \\
\hline$\omega_{s e}$ & $6.89 .10^{5} \mathrm{rad} / \mathrm{s}$ \\
\hline$I_{s d 0}=0.95 \mathrm{~A}$ & $I_{s q 0}=2.88 \mathrm{~A}$ \\
\hline$V_{c d 0}=-143.61 \mathrm{v}$ & $V_{c q 0}=142.29 \mathrm{v}$ \\
\hline$I_{d 0}=-8.27 \mathrm{~A}$ & $I_{q 0}=-6.42 \mathrm{~A}$ \\
\hline
\end{tabular}

\section{REFERENCES}

1. NAMADMALAN, A., J. S. MOGHANI, Single-Phase Current Source Induction Heater with Improved Efficiency and Package Size, Journal of Power Electronics, Vol. 13, no. 2, 2013, pp. 322-328.

2. BAL, G., S. ONCU, E. OZBAS, SelfOscillated Induction Heater for absorption Cooler, Elektronika IR Elektrotechnika, Vol. 19, no.10, 2013, pp. 45-48.

3. CHUDJUARJEEN, S., A. SANGSWANG, C. KOOMPAI, An Improved LLC Resonant Inverter for Induction-Heating Applications with Asymmetrical Control, IEEE Transactions on Industrial Electronics, vol.58, no.7, 2011, pp. 2915-2925.

4. KUKKU, J., K. K. BENNY, High Frequency LLC Resonant Inverter for Induction Heating with Asymmetrical Control, Int. Jour. of Advanced Information Science and Technology, Vol. 30, no. 30, 2014, pp. 257-262.

5. BOOMA, N., R. R. SATHI, V. PRADEEP, Comparative Analysis of Various Modulation Strategies for Induction Heating System, Applied Mechanics and Materials, Vol. 622, 2014, pp. 39-43.

6. KONGSAKORN, P., A. JANGWANITLERT, A Two-Output High Frequency SeriesResonant Induction Heater, International
Conference on Electrical Engineering / Electronics Computer Telecommunications and Information Technology (ECTI-CON), Chaing Mai, 19-21 May 2010.

7. JITTAKORT, J., S. YACHIANGKAM, A. SANGSWANG, S. NAETILADDANON, C. KOOMPAI, S. CHUDJUARJEEN, A VariableFrequency Asymmetrical Voltage Cancellation Control of Series Resonant Inverters in Domestic Induction Cooking, $8^{\text {th }}$ International Conference on Power Electronics and ECCE Asia (ICPE \& ECCE), Jeju, May 30June 3, 2011.

8. YACHIANGKAM, S., A. SANGSWANG, S. NAETILADDANON, C. KOOMPAI, S. CHUDJUARJEEN, Resonant Inverter with a Variable-Frequency Asymmetrical VoltageCancellation Control for Low Q-Factor Loads in Induction Cooking, Proc. of the $14^{\text {th }}$ European Conference on Power Electronics and Applications (EPE 2011), Birmingham, Aug. 30-Sept. 1, 2011.

9. HELAIMI, M., M. BENGHANEM, B. BELMADANI, An Improved $\mathbf{P I}^{\lambda}$ Controller for Resonant Inverter Induction Heating Systems under Load and Line Variations, Studies in Informatics and Control, Vol. 21, no. 4, 2012.

10. ROY, C. P., Control Analysis of a High Frequency Resonant Inverter for Induction Cooking Application, Int. Journal of Research in Engineering and Technology, Vol. 4, no. 3, 2015, pp. 340-348.

11. HONG-YU, L., L. XIADONG, L. MING, H. SONG, A Linearized Large Signal Model of an LCL-Type Resonant Converter, Energies. Vol. 8, 2015, pp. 1848-1864.

12. HU, M., N. FRÖHLEKE, J. BÖCKER, SmallSignal Model and Control Design of LCC Resonant Converter with a Capacitive Load Applied in Very Low Frequency High Voltage Test System, IEEE on Energy Conversion Congress and Exposition ECCE'2009, San Jose, 2009, pp. 2972-2979.

13. KONGSAKORN, P., A. JANGWANITLERT, Small Signal Modeling of a Two-Output High Frequency Series-Resonant Induction Heater", $11^{\text {th }}$ International Conference on Electrical Engineering, Electronics, Computer, Telecommunications and Information Technology (ECTI-CON), Nakhon Ratchasima, 14-17 May 2014.

14. POPESCU, M. A. BITOLEANU, Power Control System Design in Induction Heating with Resonant Voltage Inverter, Journal of Automation and Control Engineering, Vol. 2, 
no. 2, 2014, pp. 195-198.

15. POPESCU, M., A. BITOLEANU, E. SUBTIRELU, Design and Performance of the Voltage Control Loop in Induction Heating Systems with L-LC Resonant Inverters, Annals of the University of Craiova, Electrical Engineering series, no. 37, 2013, pp. 39-43.

16. NAMADMALAN, A., J. S. MOGHANI, J. MILIMONFARED, A Current-Fed Parallel Resonant Push-Pull Inverter with a New Cascaded Coil Flux Control for Induction Heating Applications, Journal of Power Electronics, Vol. 11, no. 5, September 2011.

17. SZELITZKY, T., E. H. DULF, Adaptive Control in Series Load PWM Induction Heating Inverters, Intl. Journal of Electronics, Vol. 100, no. 12, 2013, pp. 1714-1723.

18. GANG, Z., W. CHAO, G. YUNWANG, B. TING, A Frequency Adaptive Controller for Induction Heating Power Supply, Third Global Congress on Intelligent Systems (GCIS), Wuhan, 6-8 Nov. 2012.

19. PAESA, D., C. FRANCO, S. LIORENTE, G. LOPEZ-NICOLA, C. SAGUES, Adaptive Simmering Control for Domestic Induction Cookers, IEEE Transaction on Industry Applications, vol. 47(5), 2011, pp. 2257-2267.

20. LUCIA, O., J. M. BURDIO, I. MILLAN, J. ACERO, D. PUYAL, Load-Adaptive Control Algorithm of Half-Bridge Series Resonant Inverter for Domestic Induction Heating, IEEE Transactions on Industrial Electronics, Vol. 56, no. 8, 2009, pp. 3106-3116.

21. SWARNKAR, P., S. JAIN, R. K. NEMA, Effect of Adaptation Gain in Model Reference Adaptive Controlled Second Order System, Engineering, Technology \& Applied Science Research, Vol. 1, no. 3, 2011 pp. 70-75.

22. SAR, S. K., MRAC Based PI Controller for Speed Control of D.C. Motor Using Lab View, WSEAS Transactions on Systems and Control, Vol. 09, 2014, pp. 10-15.
23. XIAO, S., Y. LI, J. LIU, A Model Reference Adaptive PID Control for Electromagnetic Actuated Micro-positioning Stage, IEEE Inter. Conf. on Automation Science and Engineering (CASE), Seoul, Korea. August 2024, 2012, pp. 97-102.

24. VIJUla, A., N. DEVARAJAN, Design of Decentralised PI Controller using Model Reference Adaptive Control for Quadruple Tank Process, International. Journal of Engineering and Technology, Vol. 5, no. 6, 2014, pp. 5057-5066.

25. GHANEM, S. A. M., H. SHIBLY, D. SOEFFKER, Enhanced Adaptive Controller using Combined MRAC and STC Adaptive Control Approaches for the Control of Shape Memory Alloy Wire, Proceedings of the World Congress on Engineering and Computer Science 2010 WCECS 2010, October 20-22, 2010, San Francisco, USA.

26. TORRES, L. H. S., L. SCHNITMAN, C. A. V. V. JÚNIOR, J. A. M. F. de SOUZA, Feedback Linearization and Model Reference Adaptive Control of a Magnetic Levitation System, Studies in Informatics and Control, Vol. 21, no. 2, 2012.

27. KOROPOULI, V., A. GUSRIALDI, D. LEE, ESC-MRAC of MIMO Systems for Constrained Robotic Motion Tasks in Deformable Environments, European Control Conference (ECC) June 24-27, 2014. Strasbourg, France.

28. HAGHI, P., K. B. ARIYUR, Adaptive Feedback Linearization of Nonlinear MIMO Systems Using ES-MRAC, American Control Conference (ACC) Washington, DC, USA, June 17-19, 2013.

29. AHMED, N. A., Three-phase High Frequency AC Conversion Circuit with Dual Mode PWM/PDM Control Strategy for High Power IH Applications, PWASET Vol. 35, 2008, pp 371-377. 